\title{
Prevalence of noroviruses in children hospitalized for acute gastroenteritis in Hohhot, China, 2012-2017
}

\author{
Hui-ying $\mathrm{Li}^{1 \dagger}$, Yu-geng Zhang ${ }^{2 \dagger}$, Xia Lei ${ }^{2}$, Jian Song ${ }^{2}$ and Zhao-jun Duan ${ }^{1 *}$ (D)
}

\begin{abstract}
Background: Noroviruses (NVs) are an important cause of acute gastroenteritis (AGE) worldwide. There are limited data on the prevalence and molecular characterization of NVs in children in Hohhot, China.

Methods: Between January 2012 and December 2017, 1863 stool samples were collected at Maternal and Child Health Hospital in Hohhot. All samples were screened for NVs by real-time reverse transcription polymerase chain reaction (real-time RT-PCR).

Results: NVs were detected in $24.15 \%$ of these inpatient cases, ranging from 12.78 to $32.92 \%$ in different years. NV was detected throughout the year, with a peak in winter. Based on sequence analysis of the partial VP1 gene, the 306 identified NV strains were divided into six genotypes: GIl.3 (71.24\%), GIl.4 (23.53\%), and GIl.2, GIl.5, GIl.6, and Gll.13 (total 5.23\%). Based on further sequence analysis of the RNA-dependent RNA polymerase (RdRp), GIl.P12/GIl.3, Gll.Pe/GIl.4, and GIl.P4/GIl.4 were identified as predominant genotypes, accounting for $92.6 \%$ of genotyped strains. The median age of the children with NV infection was 8.0 (range 0-59) months. However, children infected with Gll.3 were younger (median 7.0 months) than Gll.4-positive patients (median 10.0 months).
\end{abstract}

Conclusion: NV contributed greatly to AGE among hospitalized children in Hohhot in China. Continuous surveillance is important for understanding the local prevalence and characterization of NV.

Keywords: Norovirus, Children, Acute gastroenteritis, Genotype

\section{Background}

NVs are a leading cause of epidemic gastroenteritis [1], responsible for at least $90 \%$ of all non-bacterial gastroenteritis cases and $50 \%$ of all gastroenteritis outbreaks worldwide [2, 3]. All age groups can be infected by NVs, especially children, the old, and the immunosuppressed. The acute gastroenteritis which caused by NVs has become the second infectious disease due to its highly transmission with fecal-oral route and lowly infectious dose $[4,5]$. In the developing countries, more than 200, 000 deaths per year are caused by NVs infection [6].

NVs are belonging to Caliciviridae, with a 7.5-kb-long ssRNA genome. Three different open reading frames

\footnotetext{
* Correspondence: zhaojund@126.com

${ }^{\dagger} \mathrm{Hui}-\mathrm{ying} \mathrm{Li}$ and Yu-geng Zhang contributed equally to this work.

${ }^{1}$ National Institute for Viral Disease Control and Prevention, Chinese Center for Disease Control and Prevention, 155 Changbai Rd., Changping District, Beijing, People's Republic of China

Full list of author information is available at the end of the article
}

(ORFs) encode different proteins of NVs [7]. Six nonstructural proteins are encoded by ORF1, such as p28, $\mathrm{VPg}, 3 \mathrm{CL}^{\mathrm{pro}}$, and the structural proteins are encoded by ORF2 (VP1) and ORF3 (VP2) to form the capsid of NVs. [7]. Total seven genogroups (GI, GII, GIII, GIV, GV, GVI, and GVII) NVs are classified by the identities of VP1 and RdRp amino acid sequences of NVs $[8,9]$. Human beings are the major host to genogroups GI, GII, and GIV NVs, however, other genogroups NV are mainly infected with animals. The epidemic of human acute gastroenteritis are mainly caused by GI or GII NVs $[8,10]$ and the recombination between ORF1 and ORF2 [11], antigenic variation of P domain of VP1 [12] are contributed to generate novel NV strains. The emerging of NVs leading to the epidemic of human acute gastroenteritis in the worldwide, at hence, it is important to determine both the capsid and RdRp genotypes for strain characterization. 
Despite the large number of NV genotypes cocirculating in children over the past decade, genotypes GII.4 and GII.3 have predominated worldwide [13-17]. Up to nowadays, six outbreaks of acute gastroenteritis are associated with at least seven distinct GII.4 NV variants [14]. Three major clusters (I-III) and five smaller genetic lineages $(\mathrm{A}-\mathrm{E})$ have been identified in the VP1 region of GII.3 NV [13, 18]. Global surveillance data over the years indicated that the majority of outbreaks of NV were caused by GII.4, but the recent NV outbreak strains in Asia were GII.2 and GII.17 [1, 19, 20]. Furthermore, other genotypes were co-circulating, with different epidemiological patterns in different regions $[1,17]$.

China is a vast country, and the prevalence of NV varies by region $[1,19,21,22]$. However, reports and knowledge of routine sporadic NV disease in northern China have been limited. Furthermore, in several recent years, rare NV genotypes (GII.2, GII.6, and GII.17) have caused prevalent outbreaks in China $[19,20]$ and other parts of Asia [23, 24]. Therefore, it is important to explore the NV strains in sporadic AGE cases, which may also aid in understanding the prevalence of human $\mathrm{NV}$ in the population. In the present study, we explored the epidemiological and molecular characteristics of NVs in children younger than 5 years hospitalized for AGE from 2012 through 2017 in Hohhot, China.

\section{Methods}

\section{Specimen collection}

Between January 2012 and December 2017, 1863 fecal samples were collected from children younger than 5 years admitted to Maternal and Child Health Hospital in Hohhot with acute gastroenteritis (AGE). AGE was defined as two or more loose stools within a 24-h period. Stool specimens were collected within 7 days after the onset of the disease. All AGE cases admitted to the hospital were enrolled. All specimens were sent to the Inner Mongolia Centers for Disease Control and Prevention for NV detection, and the NV-positive samples were sent to the Institute for Viral Disease Control and Prevention, China $C D C$, for further testing and sequencing. Demographic and clinical data were collected using a standard questionnaire. Oral informed consent was obtained from the guardians of all hospitalized children for samples and data collection.

\section{RNA extraction and viral detection}

Stool samples were prepared with phosphate-buffered saline solution to a final concentration of $10 \%$. Viral RNA was extracted from $200 \mu \mathrm{L}$ of a $10 \%$ stool suspension using the Viral Nucleic Acid Extraction Kit II (Geneaid, China), according to the manufacturer's instructions. The RNA was then subjected to one-step real-time RT-PCR targeting NV sequences at the
ORF1/ORF2 junction for NV detection, as described previously [25].

\section{Capsid and RdRp gene amplification}

Following NV detection, positive samples were tested by conventional RT-PCR for amplification of the partial RdRp and VP1 gene regions of NV using the QIAGEN One-Step RT PCR Kit (QIAGEN). The 5'-end capsid gene (region $\mathrm{C}$ in ORF2) was amplified with oligonucleotide primer sets G1SKF/R and COG2F/G2SKR for $330 \mathrm{bp}$ of the GI and $344 \mathrm{bp}$ of the GII capsid genes respectively, as previously described [26]. The 3'-end of the RdRp gene (region A in ORF1) was amplified using a published oligonucleotide primer set, P290/P289 for a 319-bp fragment, as previously described [27]. The PCR products were visualized on agarose gels.

\section{Sequencing and phylogenetic analysis}

All PCR products were purified and sequenced by Invitrogen Trading (Shanghai). The sequence identity was searched using the Basic Local Alignment Search Tool (BLAST) (https://blast.ncbi.nlm.nih.gov/Blast.cgi) multiple sequence alignment, and a phylogenetic tree was constructed using MEGA 7 [28]. The dendrogram was determined using the neighbor-joining method in MEGA7. Bootstrap resampling (1000 replications) was used and bootstrap values $\geq 75 \%$ are shown. The partial nucleotide sequences determined in this study were submitted to GenBank (acc. no. MK319217 to MK319535).

\section{Statistical analysis}

Data were analyzed using SPSS 19.0 and Excel (MS office 2007). Numbers and percentages were computed for categorical variables. Categorical variables and proportions were compared using a two-sided chi-square test or Fisher's exact test where appropriate. The 95\% confidence intervals (95\% CI) were estimated using the binomial exact method and $P$-values $<0.05$ were considered statistically significant.

\section{Results \\ Epidemiological characteristics of NV in AGE in Hohhot} From January 2012 to December 2017, 1863 AGE cases were enrolled in our study $(402,370,223,322,251$, and 295 in 2012 to 2017, respectively). Males accounted for $60.98 \%$ (1136/1863) and females $39.02 \%$ (727/1863). The median age was 8.0 (range 0-59) months (Table 1).

Overall, the NV positivity rate was $24.15 \%$ (450/1863). From 2012 to 2017, NV positivity ranged from 17.94 to $32.92 \%$. The highest positivity was observed in 2015 (Table 1). Gender was not significantly associated with $\mathrm{NV}$ infection (male/female, $X^{2}=1.956, P=0.162$ ). The detection rates for children $0-11,12-23,24-35,36-47$, 
Table 1 Demographic characteristics of acute gastroenteritis patients admitted to the sentinel hospital in Hohhot, in 2012-2017

\begin{tabular}{llll}
\hline Characteristics & Total Tested & No. of norovirus Positive & Rate of Norovirus positive \\
\hline $\begin{array}{l}\text { Participants } \\
\text { Gender, } n=1863\end{array}$ & 1863 & 450 & $24.15 \%$ \\
Males & 1136 & 287 & $25.26 \%$ \\
Females & 727 & 163 & $22.42 \%$ \\
Age group (month), $n=1863$ & & \\
$0-11$ & 1258 & 308 & $24.48 \%$ \\
$12-23$ & 483 & 106 & $26.67 \%$ \\
$24-35$ & 75 & 20 & $22.95 \%$ \\
$36-47$ & 32 & 8 & $25.00 \%$ \\
$48-59$ & 15 & 8 & $53.33 \%$ \\
Year, $n=1863$ & & & \\
2012 & 402 & 88 & $21.89 \%$ \\
2013 & 370 & 87 & $23.51 \%$ \\
2014 & 223 & 40 & $17.94 \%$ \\
2015 & 322 & 106 & $32.92 \%$ \\
2016 & 251 & 55 & $21.91 \%$ \\
2017 & 295 & 74 & $25.08 \%$ \\
\hline & & & $P=0.001$ \\
& & &
\end{tabular}

and 48-59 months were $24.48 \%$ (308/1258), 26.67\% (106/ 483), $22.95 \%$ (20/75), $25 \%(8 / 32)$, and $53.33 \%(8 / 15)$, respectively, and they were not significantly different $\left(\chi^{2}=8.602, P=0.072\right)$. However, the total number of AGE cases and number of NV cases in the 0- to 23month age group were much higher than those of the 24 - to 47-month age group. Of NV AGE, $14 \%$ occurred before the age of 3 months. By the age of 24 months, nearly $97 \%$ of $\mathrm{NV}$-positive cases had occurred. The cumulative NV-positive rate by age indicated that $0-23$ months was the main age group for $\mathrm{NV}$ infection (Fig. 1).

NV infection can occur throughout the year (Fig. 2). Every year, NV infection had three peaks. The highest

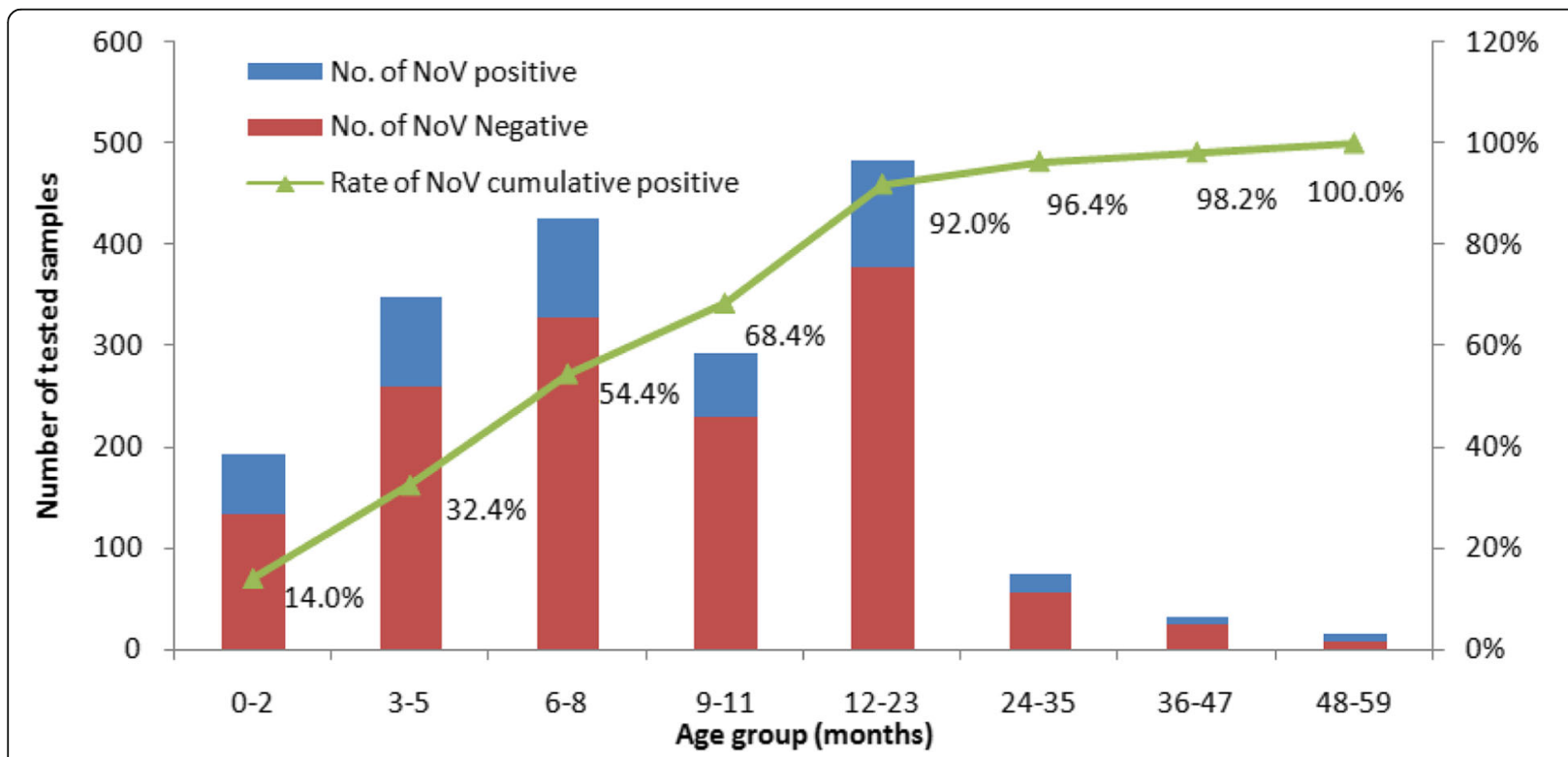

Fig. 1 Age distribution of NV cases in children aged < 5 years in Hohhot, 2012-2017. The tested sample number (left $y$-axis) and the percentage (right $y$-axis) of NV cumulative positive cases isolated from stool samples and collected from children presenting with acute gastroenteritis in Hohhot are plotted against age groups ( $x$-axis) 


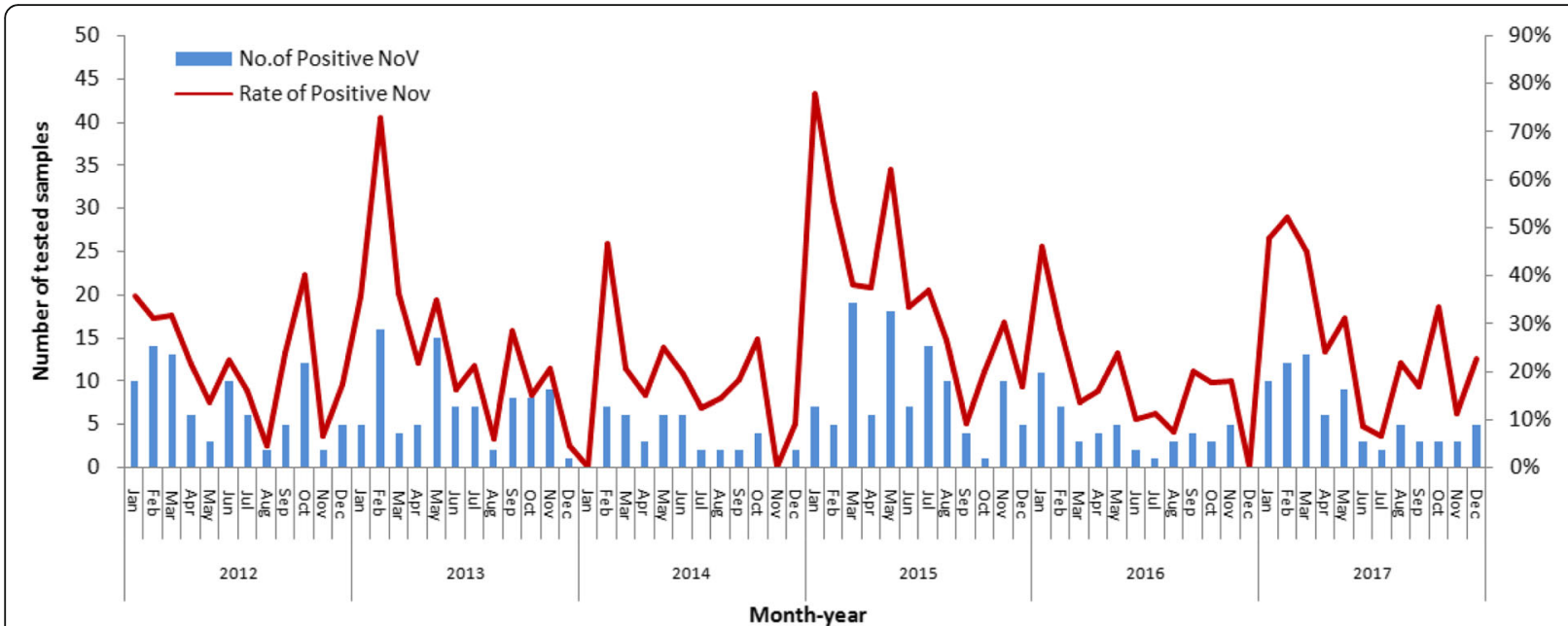

Fig. 2 Seasonal distribution of NV cases among children aged $<5$ years in Hohhot. The absolute number (left $y$-axis) and percentage (right $y$-axis) of NV-positive cases isolated from stool samples and collected from children presenting with acute gastroenteritis in Hohhot are plotted against the month and year ( $x$-axis)

peak was from January to March, with 40 80\% positivity. Two small peaks occurred in May and September, with $30 \%$ positivity.

\section{Genotyping of NV}

Of the $450 \mathrm{NV}$-positive samples, 332 (74\%) were genotyped. NV geno-grouping revealed that all belonged to GII and none belonged to GI. Of the 332 genotyped samples, both the RdRp and capsid genes were genotyped in 296 samples, only the RdRp gene was determined in 26 samples, and only the capsid gene in 10 samples. Based on the capsid gene, strain GII.3 was predominant with $71.24 \%(218 / 306)$ prevalence, followed by strains GII.4 (23.53\%, 72/306), GII.2 (2.61\%, 8/306), GII.13 (1.63\%, 5/306), GII.6 (0.65, 2/306), and GII.5 $(0.33 \%, 1 / 306)$. Based on the RdRp gene, GII.P12 was most prevalent at $71.42 \%(230 / 322)$, followed by GII. Pe (12.42\%, 32/322), GII.P4 (11.18\%, 36/322), GII.P16 $(4.04 \%, 13 / 322)$, GII.P7 $(0.62 \%, 2 / 322)$, and GII.P22 $(0.31 \%, 1 / 322)$.

The analysis of the 296 sequences of both the RdRp and capsid genes showed that at least $11 \mathrm{RdRp} /$ capsid NV genotypes circulated in Hohhot during the last 6 years (Table 2). The most common genotype was the GII.12/GII.3 recombinant (69.6\%), followed by the GII.Pe/GII.4 (13.2\%) and GII.P4/GII.4 (9.8\%) recombinants. The remaining identified recombinant genotypes (GII.P16/GII.2, GII.P12/GII.4, GII.P16/GII.4, GII.P4/ GII.3, GII.P16/GII.13, GII.P12/GII.13, GII.P12/GII.12, and GII.P22/GII.5) were uncommon.

Ninety-two percent $(414 / 450)$ of the NV cases occurred in the 0- to 23-month age group. Further analysis showed a difference between the age distributions of GII.3- and GII.4-positive children (Fig. 3). From 2012 to 2017, 78\% of the GII.3 infections occurred in children aged 0-11 months, while $72 \%$ of the GII.4 infections occurred in children aged 6-24 months. Children infected with GII.3 were younger (median 7.0 months) than GII.4-positive patients (median 10.0 months) ( $P=0.021$, Mann-Whitney U test).

\section{Phylogenetic analysis of NV}

In Hohhot, GII.3 was the predominant genotype from 2012 to 2017 , accounting for $58,78,76,75,71$, and $74 \%$ in the respective years (Fig. 4). Phylogenetic analysis of

Table 2 Distribution of norovirus RdRp and capsid genotypes among children aged $<5$ years in Hohhot, 2012-2017

\begin{tabular}{|c|c|c|c|c|}
\hline \multicolumn{3}{|c|}{ Genotype } & \multirow{2}{*}{$\begin{array}{l}\text { Total } \\
\text { recombinants }\end{array}$} & \multirow{2}{*}{$\begin{array}{l}\text { Proportion of } \\
\text { recombinants }\end{array}$} \\
\hline$\overline{\text { Capsid }}$ & & $\mathrm{RdRp}$ & & \\
\hline \multirow[t]{7}{*}{ Gll.4 } & $\begin{array}{l}\text { the New Orleans } 2010 \\
\text { variant }\end{array}$ & Gll.P4 & 2 & $9.8 \%$ \\
\hline & $2006 b$ variant & & 13 & \\
\hline & Sydney 2012 variant & & 14 & \\
\hline & 2006b variant & Gll.Pe & 1 & $13.2 \%$ \\
\hline & Sydney 2012 variant & & 38 & \\
\hline & Sydney 2012 variant & Gll.P12 & 2 & $0.7 \%$ \\
\hline & Sydney 2012 variant & Gll.P16 & 1 & $0.3 \%$ \\
\hline \multirow{2}{*}{\multicolumn{2}{|c|}{ Gll.3 }} & Gll.P12 & 206 & $69.6 \%$ \\
\hline & & Gll.P4 & 3 & $1.0 \%$ \\
\hline \multicolumn{2}{|l|}{ Gll.2 } & Gll.P16 & 8 & $2.7 \%$ \\
\hline \multirow{2}{*}{\multicolumn{2}{|c|}{ Gll.13 }} & Gll.P16 & 4 & $1.4 \%$ \\
\hline & & Gll.P12 & 1 & $0.3 \%$ \\
\hline \multicolumn{2}{|l|}{ Gll.5 } & Gll.P22 & 1 & $0.3 \%$ \\
\hline \multicolumn{2}{|l|}{ Gll.6 } & Gll.P7 & 2 & $0.7 \%$ \\
\hline \multicolumn{2}{|l|}{ Total } & & 296 & \\
\hline
\end{tabular}




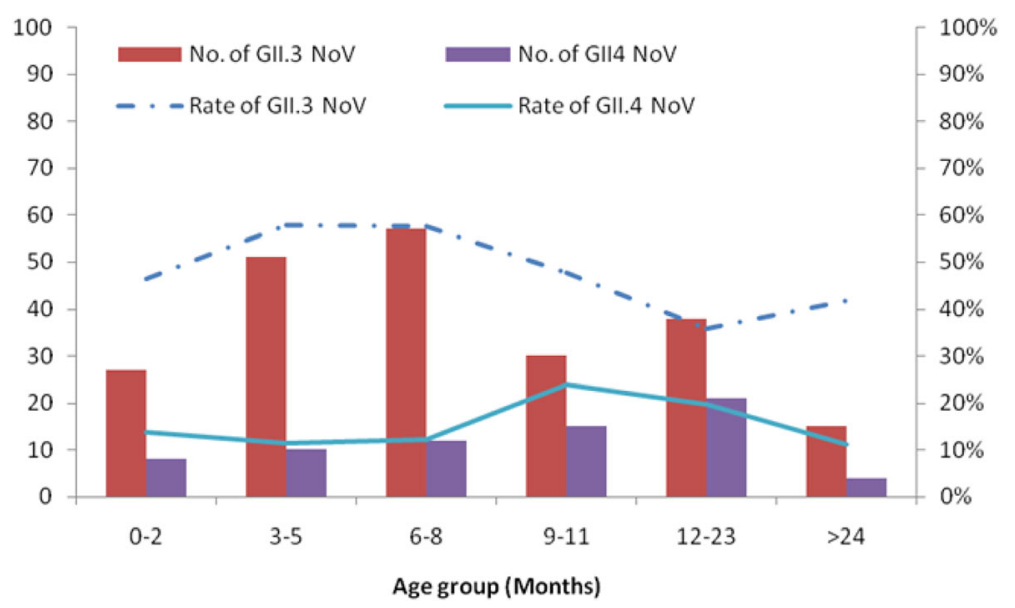

Fig. 3 Age group distribution (months) of children aged < 5 years hospitalized for AGE caused by NV GIl.3 and GII4 in Hohhot, 2012-2017. The percentages were calculated with respect to total NV of each analyzed genotype

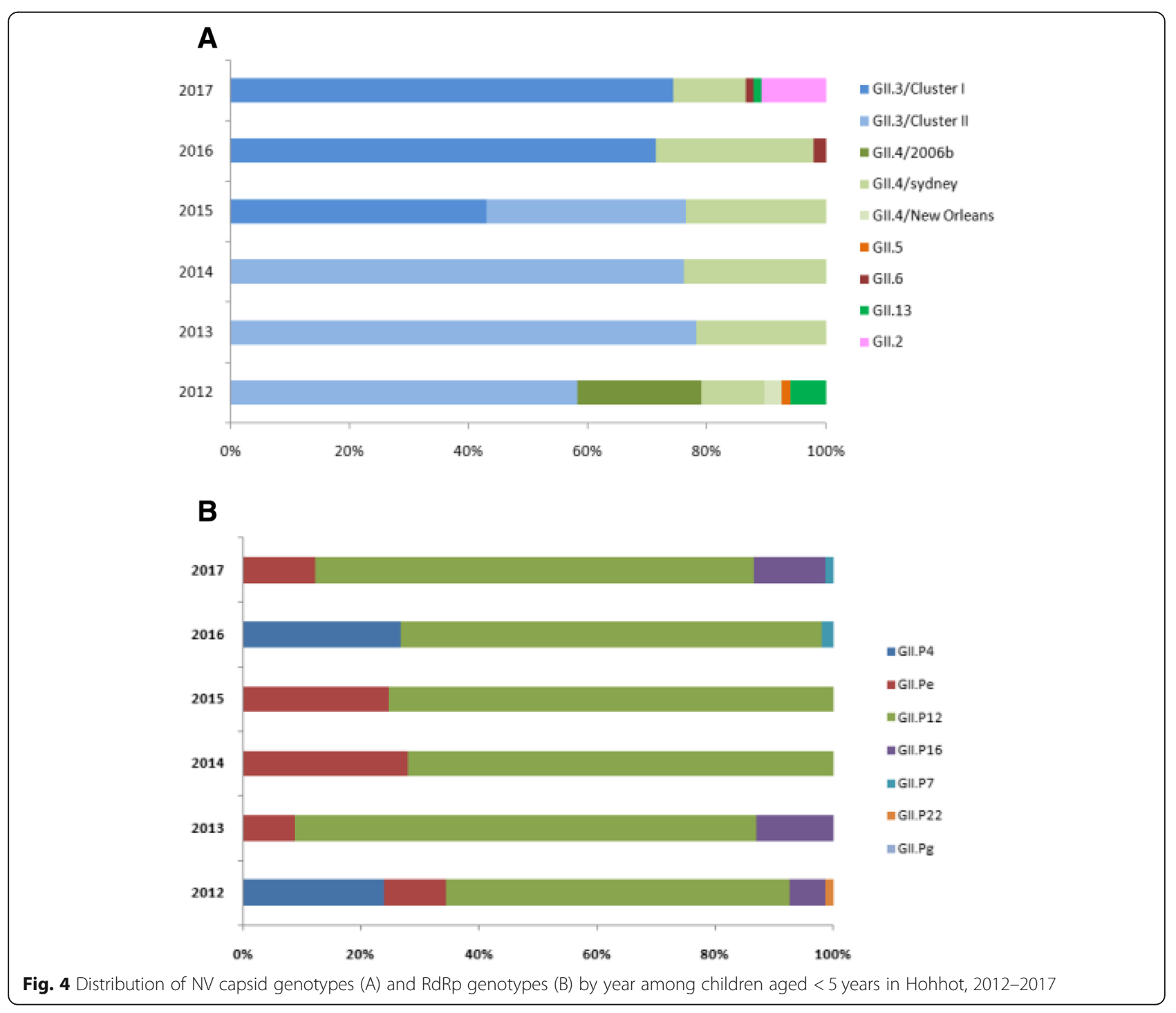


the partial capsid gene sequences demonstrated that all of the Hohhot GII.3 strains $(n=248)$ grouped into two clusters (I and II) (Fig. 5). We obtained 30 reference sequences of Hohhot NoV GII3 strains from 2008 to 2010 in GenBank (acc. no. MK319301-MK319330), which belong to GII.3/cluster I. Whereas the GII.3/cluster II strain was the main epidemic strain in 2012-2014, GII.3/cluster I was not detected. Nevertheless, in 2015, the GII.3/cluster I strain began to re-emerge and became common simultaneously with the GII.3/cluster II strain. From 2016 to 2017, the former became the main epidemic strain and the latter was not detected. Based on the RdRp genotype (Table 2), the GII.3/cluster I and GII.3/cluster II strains were both detected in combination with GII.P12 and GII.P4, and the latter was detected in combination with GII. Pe and GII.P6.

In Hohhot, GII.4 was the second-most dominant genotype from 2012 to 2017, accounting for 34, 22, 24, 23,27 , and $12 \%$ in the respective years (Fig. 4). During the study period, three variants of the GII.4 genotype were identified. Fourteen identified GII.4 strains were clustered closely with the GII.4/2006b variant, sharing 98.1-100\% identity with the AB291542/GII.4/Kobe034/ 2006/JAN strain. Fifty-six identified with the GII.4/Sydney 2012 variants and shared $98.1-100 \%$ identity with the JX459908/GII.4/Sydney/2012/AU strain. Two were the GII.4/New Orleans 2009 variant, sharing 99.3 and 99.7\% with the KX354038/GII.4/New Oreans/2009/US strain, respectively. We obtained 61 reference sequences of Hohhot NV GII.4 strains from 2008 to 2010 in GenBank (acc. no. MK319151-MK319171, MK319176MK319214, and MK319215-MK319216), 59 of which belonged to the GII.4/2006b variant, and 2 to the GII.4/ New Orleans 2009 variant. In 2012, the predominant strain was the GII.4/2006b variant, but after 2013, the GII.4/Sydney 2012 variant replaced the GII.4/2006b variant as the epidemic strain, and the GII.4/2006b variant was not detected. Based on the RdRp genotype (Table 2), the GII.4/2006b variant was detected in combination with GII.P4; the GII.4/Sydney 2012 variant was detected in combination with GII. Pe, GII.P4, GII.P12, and GII.P6; and the GII.4/New Orleans 2009 variant was detected in combination with GII.P4.

\section{Discussion}

In the present study, we conducted long-term surveillance for $\mathrm{NV}$-associated gastroenteritis in hospitalized children younger than 5 years of age in Hohhot, Inner Mongolia, China. From 2012 to 2017, the NV positivity rate was $24.15 \%$ in Hohhot, which was close to that in Wuhan (2007-2010, 25.9\%), but higher than that in other parts of China [29]. This result indicates the high activity of NV in recent years in Hohhot. Furthermore, 93\% (1741/1863) of AGE cases were children aged 0 to
23 months, and NV positivity was higher in the 0-23month age group than in children older than 24 months, which implies that young children are more vulnerable to NV infection. This result is consistent with previous studies $[15,22,30,31]$, indicating that intervention approaches such as a vaccine for $\mathrm{NV}$ infection should be implemented for children under 24 months of age.

According to a systematic review of the global seasonality of NV, in the Northern Hemisphere NV usually peaks in cold seasons, whereas it does not exhibit a consistent summer or winter peak in the Southern Hemisphere [32]. In southeastern China, NV infections were detected mainly in the spring and summer [26], whereas in North China, NV infections occurred commonly in the winter [33, 34]. However, in this study we found three peaks of NV infection per year in Hohhot. The highest peak was observed in winter, and two small peaks occurred in spring and fall. Hohhot is located in the northern part of China in the continental Mongolian plateau, with short, hot, rainless summers, and long, severe, cold, snowless winters. This differs from the climate in the other northern regions in China. The seasonal pattern of $\mathrm{NV}$ in Hohhot might be related to this unique local climate.

The oldest GII.3 NV strain identified to date is from a 1983 sample isolated in the Goulburn Valley of Australia [13], and GII.3 has been reported to be the major cause of sporadic pediatric NV infection [15, 17, 35, 36]. In China, early reports on NV showed GII.3 was prevalent in 1999 [37, 38], and until now, GII.3 was reported as the dominant genotype next to GII.4 in sporadic NV infection $[39,40]$. However, in this study, we found that NV GII.3 was the most prevalent strain among children hospitalized for AGE from 2012 to 2017. Hohhot, located in the North China Plateau, is vast and sparsely populated, and lags behind the developed cities of our country in socioeconomic development and the convenience of transportation. Population flow and economic trade in Hohhot are infrequent. During this period, the GII.P12/GII.3 recombinant was the most common genotype, and it was also detected more frequently in China and Japan than in other parts of the world [14, 34, 36]. The GII.3 strains identified in our study were grouped into two clusters (I and II) in a phylogenetic analysis of the capsid gene sequences. Lacking early NV surveillance data from Hohhot, it is not yet possible to determine whether GII.3/cluster II strains emerged and spread before 2012. However, our results suggested the hypothesis of an alternating epidemic pattern between GII.3/cluster I strains and GII.3/cluster II strains in Hohhot. Because only partial capsid gene sequences were obtained, rather than the complete VP1 region, or even the longer genome including the ORF1/ORF2 overlap region, we cannot clearly delineate the evolutionary 


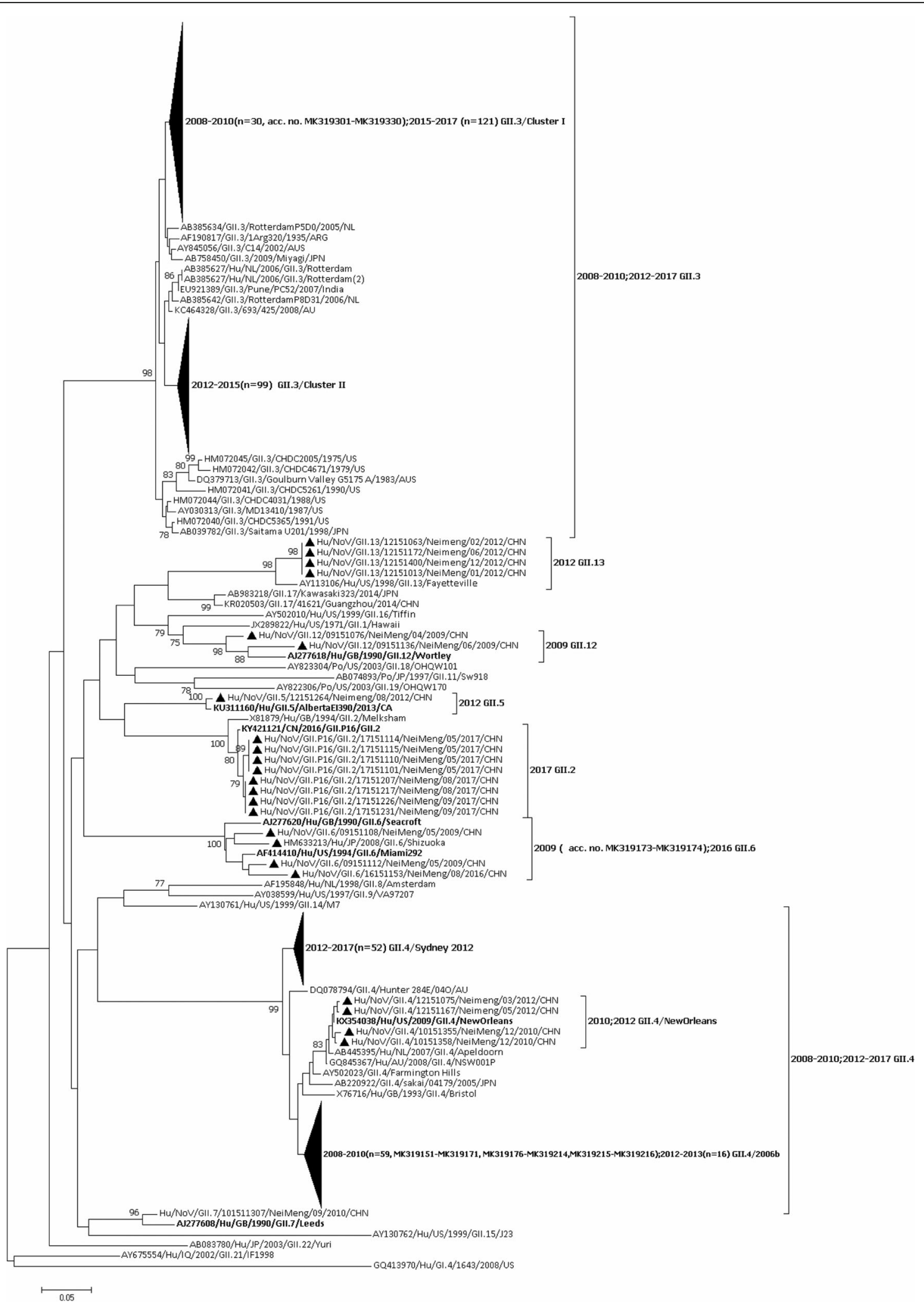

Fig. 5 (See legend on next page.) 
(See figure on previous page.)

Fig. 5 Phylogenetic analysis of the NV viral protein 1 major capsid gene. Nucleotide sequences spanning nucleotides $5081-5362$ (length = 282 nt) of NVs isolated in Hohhot were aligned with reference strains obtained from GenBank. The reference strains of Hohhot NoV strains from 2008 to 2010 are GenBank acc. Nos. MK319151-MK319216 and MK319301-MK319330. The phylogenetic tree was constructed based on the nucleotide sequences using the neighbor-joining method with bootstrap analysis of 1000 replicates using MEGA ver. 7.0. Bootstrap values $>75 \%$ are shown

characterization of GII.3 strains; this gap in knowledge should be addressed in the future.

Furthermore, a broad genetic diversity of NV GII 4 genotypes among children hospitalized for AGE was found in Hohhot. From 2006 to 2011, the GII.4/2006b variant was the predominant cause of sporadic NV cases and outbreaks in China and Japan [41-43]. However, this strain was replaced by the GII.4/Sydney 2012 strain in October 2012, and this strain caused a worldwide increase in NV outbreaks [44]. GII.4/Sydney 2012 was first identified in Australia, France, and New Zealand, and subsequently isolated in the United States, Belgium, Denmark, Scotland, Japan, and China. Of note, after 2012, the GII.4/Sydney 2012 variant was the dominant epidemic strain in Hohhot and most other regions of China, both in sporadic NV cases and NV outbreaks [19, 21]. Previous studies show GII.4 usually caused epidemics in adult populations, whereas GII.3 NV was prevalent in young children and infants $[45,46]$. The reasons for the difference between GII.4 and GII.3 are still unknown. Perhaps a variety of factors account for it, including cross protection from heterologous strains or the minimal infectious dose necessary to cause disease. More studies are needed to address this issue.

Unlike neighboring cities and other parts of China, where emerging GII.P17-GII.17 NVs caused outbreaks during 2014-2015, no GII.P17-GII.17 was found in children hospitalized for AGE in Hohhot in 2015. Previous reports showed that infection with the emergent GII.P17-GII.17 was more likely to occur in older children and adults [47], which may be the reason for negative detection of GII.P17-GII.17 in Hohhot, with 93\% of AGE cases among children ages 0 to 23 months. However, the exact mechanism for the emergence, prevalence, and age preference of GII.P17GII.17 remains unknown.

NV recombination was genetically characterized via analysis of regions from both the capsid gene and RdRp gene. In our study, lacking the overlap genes from the RdRp and VP1 regions, the NV recombinants were not conformed and may actually have come from two different coinfecting NV genotypes. However, since 2018, a conventional RT-PCR, as developed by the US Centers for Disease Control and Prevention (Atlanta, GA, USA) (J. Vinjé, pers. comm., 2017 Mar 1, [48], has been used for amplification of partial RdRp and VP1 gene regions. This RT-PCR will be used in our future NV surveillance.

\section{Conclusions}

We found high NV prevalence in children younger than 5 years in Hohhot who were hospitalized for AGE. GII.3 $\mathrm{NV}$ was identified as the most common cause of AGE from 2012 to 2017, and circulating genotypes changed over time with the emergence of new genetic variants. Continuous monitoring with molecular genotyping is necessary for NV diseases in children and will be helpful for the local control and prevention of AGE.

\section{Abbreviations}

AGE: acute gastroenteritis; NV: norovirus; ORFs: open reading frames; RdRp: RNA-dependent RNA polymerase; real-time RT-PCR: real-time reverse transcription polymerase chain reaction

\section{Acknowledgements}

Our thanks to study participants who contributed to this study and staff of Maternal and Child Health Hospital in Hohhot for their support in sampling.

\begin{abstract}
Authors' contributions
ZJD conceived, designed, and supervised the study. HYL, YGZ, XL, and JS performed the experiments. HYL and YGZ analyzed the data. HYL and YGZ wrote the draft and ZJD revised it critically and gave final approval. All the authors have read and approved the final version of this manuscript.
\end{abstract}

\section{Funding}

This work was supported by grants from the National Key R\&D Program of China [2016YFC1201904] and National Natural Science Foundation of China [Grant No. 81290345]. The funders had no role in the study design, data collection and analysis, decision to publish, or preparation of the manuscript.

\section{Availability of data and materials}

The datasets used and/or analyzed during the current study are available from the corresponding authors on reasonable request.

\section{Ethics approval and consent to participate}

Verbal consent was a common practice in epidemiological survey and we also only taken verbal consent from the parents by the pediatrics make sure the parents fully understands the benefit and the risk to participant in the study. Only we get the verbal consent of the parents, the whole process of study will be started. All study protocols and informed consent forms were approved by the Ethic Committee of the National Institute for Viral Disease Control and Prevention, Center for Disease Control and Prevention of China. All participants provided written informed consent to participate in the studies.

\section{Consent for publication \\ Not applicable.}

\section{Competing interests}

The authors declare that they have no competing interests.

\section{Author details}

${ }^{1}$ National Institute for Viral Disease Control and Prevention, Chinese Center for Disease Control and Prevention, 155 Changbai Rd., Changping District, Beijing, People's Republic of China. ${ }^{2}$ Center for Disease Control and Prevention of Inner Mongolia Autonomous Region, Inner Mongolia010031, Hohhot, China. 
Received: 19 March 2019 Accepted: 26 June 2019 Published online: 09 July 2019

\section{References}

1. van Beek J, de Graaf M, Al-Hello H, Allen DJ, Ambert-Balay K, Botteldoorn N, Brytting M, Buesa J, Cabrerizo M, Chan M, et al. Molecular surveillance of norovirus, 2005-16: an epidemiological analysis of data collected from the NoroNet network. Lancet Infect Dis. 2018;18:545-53.

2. Kapikian AZ, Wyatt RG, Dolin R, Thornhill TS, Kalica AR, Chanock RM Visualization by immune electron microscopy of a $27-\mathrm{nm}$ particle associated with acute infectious nonbacterial gastroenteritis. J Virol. 1972;10:1075-81.

3. Patel MM, Widdowson MA, Glass RI, Akazawa K, Vinje J, Parashar UD. Systematic literature review of role of noroviruses in sporadic gastroenteritis. Emerg Infect Dis. 2008;14:1224-31.

4. Barclay L, Park GW, Vega E, Hall A, Parashar U, Vinje J, Lopman B. Infection control for norovirus. Clin Microbiol Infect. 2014;20:731-40.

5. O'Brien SJ, Sanderson RA, Rushton SP. Control of norovirus infection. Curr Opin Gastroenterol. 2018.

6. Lopman BA, Steele D, Kirkwood CD, Parashar UD. The vast and varied global burden of norovirus: prospects for prevention and control. PLoS Med. 2016; 13:e1001999.

7. Green KY: Calicivirade: the noroviruses. In Fields virology. Edited by D. M Knipe PMH, D. E. Griffin, R. A. Lamb, M. A. Martin, B. Roizman, and S. E. Straus Lippincott Williams \& Wilkins, Philadelphia, PA.; 2007: p.949-979.

8. Zheng DP, Ando T, Fankhauser RL, Beard RS, Glass RI, Monroe SS. Norovirus classification and proposed strain nomenclature. Virology. 2006;346:312-23.

9. Kroneman A, Vega E, Vennema H, Vinje J, White PA, Hansman G, Green K, Martella V, Katayama K, Koopmans M. Proposal for a unified norovirus nomenclature and genotyping. Arch Virol. 2013;158:2059-68.

10. Vinje J. Advances in laboratory methods for detection and typing of norovirus. J Clin Microbiol. 2015;53:373-81.

11. Bull RA, Tanaka MM, White PA. Norovirus recombination. J Gen Virol. 2007; 88:3347-59.

12. Lindesmith LC, Debbink K, Swanstrom J, Vinje J, Costantini V, Baric RS, Donaldson EF. Monoclonal antibody-based antigenic mapping of norovirus Gll.4-2002. J Virol. 2012;86:873-83.

13. Boon D, Mahar JE, Abente EJ, Kirkwood CD, Purcell RH, Kapikian AZ, Green KY, Bok K. Comparative evolution of Gll.3 and Gll.4 norovirus over a 31-year period. J Virol. 2011;85:8656-66.

14. Hoa Tran TN, Trainor E, Nakagomi T, Cunliffe NA, Nakagomi O: Molecular epidemiology of noroviruses associated with acute sporadic gastroenteritis in children: global distribution of genogroups, genotypes and Gll.4 variants J Clin Virol 2013, 56:185-193.

15. Zhirakovskaia EV, Tikunov AY, Bodnev SA, Klemesheva W, Netesov SV, Tikunova NV. Molecular epidemiology of noroviruses associated with sporadic gastroenteritis in children in Novosibirsk, Russia, 2003-2012. J Med Virol. 2015:87:740-53.

16. Bok K, Abente EJ, Realpe-Quintero M, Mitra T, Sosnovtsev SV, Kapikian AZ, Green KY. Evolutionary dynamics of Gll.4 noroviruses over a 34-year period. J Virol. 2009:83:11890-901.

17. Wangchuk S, Matsumoto T, Iha H, Ahmed K. Surveillance of norovirus among children with diarrhea in four major hospitals in Bhutan: replacement of Gll.21 by Gll.3 as a dominant genotype. PLoS One. 2017;12: e0184826.

18. Mahar JE, Bok K, Green KY, Kirkwood CD. The importance of intergenic recombination in norovirus Gll.3 evolution. J Virol. 2013:87:3687-98.

19. Qin SW, Chan TC, Cai J, Zhao N, Miao ZP, Chen YJ, Liu SL. Genotypic and epidemiological trends of acute gastroenteritis associated with noroviruses in China from 2006 to 2016. Int J Environ Res Public Health. 2017;14.

20. Ao $Y$, Xie $X$, Dong $X$, Jin M, Duan Z. Genetic analysis of an emerging gii.p2gii.2 norovirus associated with a 2016 outbreak of acute gastroenteritis in China. Virol Sin. 2019.

21. Chen C, Yan JB, Wang HL, Li P, Li KF, Wu B, Zhang H: Molecular epidemiology and spatiotemporal dynamics of norovirus associated with sporadic acute gastroenteritis during 2013-2017, Zhoushan Islands, China PLoS One 2018, 13:e0200911.

22. Wang YH, Zhou DJ, Zhou X, Yang T, Ghosh S, Pang BB, Peng JS, Liu MQ, Hu Q, Kobayashi N. Molecular epidemiology of noroviruses in children and adults with acute gastroenteritis in Wuhan, China, 2007-2010. Arch Virol. 2012;157:2417-24
23. Liu L, Guan H, Zhang Y, Wang C, Yang G, Ruan S, Zhao H, Han X. The prevalence of non-Gll.4 norovirus genotypes in acute gastroenteritis outbreaks in Jinan, China. PLoS One. 2018;13:e0209245.

24. Karangwa CK, Parra GI, Bok K, Johnson JA, Levenson EA, Green KY. Sequential gastroenteritis outbreaks in a single year caused by norovirus genotypes Gll.2 and GIl.6 in an institutional setting. Open Forum Infect Dis. 2017:4:ofx236

25. Kageyama T, Kojima S, Shinohara M, Uchida K, Fukushi S, Hoshino FB, Takeda N, Katayama K. Broadly reactive and highly sensitive assay for Norwalk-like viruses based on real-time quantitative reverse transcriptionPCR. J Clin Microbiol. 2003;41:1548-57.

26. Chen Y, Li Z, Han D, Cui D, Chen X, Zheng S, Yu F, Liu J, Lai S, Yan Y, et al. Viral agents associated with acute diarrhea among outpatient children in southeastern China. Pediatr Infect Dis J. 2013;32:e285-90.

27. Jiang $X$, Huang PW, Zhong WM, Farkas T, Cubitt DW, Matson DO. Design and evaluation of a primer pair that detects both Norwalk- and Sapporo-like caliciviruses by RT-PCR. J Virol Methods. 1999;83:145-54.

28. Kumar S, Stecher G, Tamura K. MEGA7: molecular evolutionary genetics analysis version 7.0 for bigger datasets. Mol Biol Evol. 2016;33:1870-4.

29. Guoping Chen, Yonglin Shi ZZJZLSWMBS. Etiological study on viral diarrhea among patients under five years old in sentinel hospital of Anhui Province (2010-2015). J of Pub Health and Prev Med. 2018;29(1):56-9.

30. Yang jiao XQ, Gao Y, Zhang S, Zhang Y, Lin G, Hao M, Zhang Y, Liang Y, Ke W, Zhao J, Ma J, Sun L. Surveillance of enteric viral pathogens among infants with diarrhea in Chaoyang district of Beijing from 2011 to 2017. Chin J Vial Dis. 2018;8(04):275-81.

31. Melhem NM, Zaraket H, Kreidieh K, Ali Z, Hammadi M, Ghanem S, Hajar F, Haidar A, Inati A, Rajab M, et al. Clinical and epidemiological characteristics of norovirus gastroenteritis among hospitalized children in Lebanon. World J Gastroenterol. 2016:22:10557-65.

32. Ahmed SM, Lopman BA, Levy K. A systematic review and meta-analysis of the global seasonality of norovirus. PLoS One. 2013;8:e75922.

33. Jin $Y$, Cheng WX, Yang XM, Jin $M$, Zhang $Q$, Xu ZQ, Yu JM, Zhu L, Yang SH, Liu N, et al: Viral agents associated with acute gastroenteritis in children hospitalized with diarrhea in Lanzhou, China J Clin Virol 2009, 44:238-241.

34. Jia LP, Qian Y, Zhang Y, Deng L, Liu LY, Zhu RN, Zhao LQ, Huang H, Zheng $\mathrm{CG}$, Dong HJ. Prevalence and genetic diversity of noroviruses in outpatient pediatric clinics in Beijing, China 2010-2012. Infect Genet Evol. 2014;28:71-7.

35. Chhabra P, Dhongade RK, Kalrao VR, Bavdekar AR, Chitambar SD. Epidemiological, clinical, and molecular features of norovirus infections in western India. J Med Virol. 2009;81:922-32.

36. Lu QB, Huang DD, Zhao J, Wang HY, Zhang XA, Xu HM, Qu F, Liu W, Cao WC. An increasing prevalence of recombinant Gll norovirus in pediatric patients with diarrhea during 2010-2013 in China. Infect Genet Evol. 2015;31:48-52.

37. Lu HX, Fang ZY, Xie HP, Tang JY, Hu HK, Zheng LS, Ye Q, Zhang Q, Zhong WM, Xi J: [Epidemiological study of human caliciviruses among children with acute diarrhea in Lulong county, 1999 - 2001]. Zhonghua Liu Xing Bing Xue Za Zhi 2003, 24:1118-1121.

38. Fang ZY, Xie HP, Lv HX, Zhang Q, Duan ZJ, Steele D, Jiang B, Jiang X: [Investigation of human calicivirus (HuCV) diarrhea among infantile and young children in China, 1999--2005]. Bing Du Xue Bao 2007, 23:9-15.

39. Tian G, Jin M, Li H, Li Q, Wang J, Duan ZJ. Clinical characteristics and genetic diversity of noroviruses in adults with acute gastroenteritis in Beijing, China in 2008-2009. J Med Virol. 2014;86:1235-42.

40. Xue C, Pan L, Zhu W, Wang Y, Fu H, Cui C, Lu L, Qiao S, Xu B: Molecular epidemiology of genogroup II norovirus infections in acute gastroenteritis patients during 2014-2016 in Pudong new area, Shanghai, China. Gut Pathog 2018, 10:7.

41. Chan-It W, Thongprachum A, Okitsu S, Nishimura S, Kikuta H, Baba T, Yamamoto A, Sugita K, Hashira S, Tajima T, et al. Detection and genetic characterization of norovirus infections in children with acute gastroenteritis in Japan, 2007-2009. Clin Lab. 2011;57:213-20.

42. Jin M, Xie HP, Duan ZJ, Liu N, Zhang Q, Wu BS, Li HY, Cheng WX, Yang SH, Yu JM, et al. Emergence of the Gll4/2006b variant and recombinant noroviruses in China. J Med Virol. 2008;80:1997-2004.

43. Yu Y, Yan S, Li B, Pan Y, Wang Y. Genetic diversity and distribution of human norovirus in China (1999-2011). Biomed Res Int. 2014;2014:196169.

44. van Beek J, Ambert-Balay K, Botteldoorn N, Eden JS, Fonager J, Hewitt J, Iritani N, Kroneman A, Vennema H, Vinje J, et al. Indications for worldwide increased norovirus activity associated with emergence of a new variant of genotype II.4, late 2012. Euro Surveill. 2013;18:8-9. 
45. Barreira DM, Ferreira MS, Fumian TM, Checon R, de Sadovsky AD, Leite JP, Miagostovich MP, Spano LC. Viral load and genotypes of noroviruses in symptomatic and asymptomatic children in southeastern Brazil. J Clin Virol. 2010:47:60-4.

46. Dey SK, Phathammavong O, Okitsu S, Mizuguchi M, Ohta Y, Ushijima H. Seasonal pattern and genotype distribution of norovirus infection in Japan. Pediatr Infect Dis J. 2010;29:e32-4.

47. Medici MC, Tummolo F, Calderaro A, Chironna M, Giammanco GM, De Grazia S, Arcangeletti MC, De Conto F, Chezzi C, Martella V. Identification of the novel Kawasaki 2014 Gll.17 human norovirus strain in Italy, 2015. Euro Surveill. 2015;20:30010.

48. Cannon JL, Barclay L, Collins NR, Wikswo ME, Castro CJ, Magana LC, Gregoricus N, Marine RL, Chhabra P, Vinje J. Genetic and epidemiologic trends of norovirus outbreaks in the United States from 2013 to 2016 demonstrated emergence of novel Gll.4 recombinant viruses. J Clin Microbiol. 2017;55:2208-21.

\section{Publisher's Note}

Springer Nature remains neutral with regard to jurisdictional claims in published maps and institutional affiliations.

Ready to submit your research? Choose BMC and benefit from:

- fast, convenient online submission

- thorough peer review by experienced researchers in your field

- rapid publication on acceptance

- support for research data, including large and complex data types

- gold Open Access which fosters wider collaboration and increased citations

- maximum visibility for your research: over $100 \mathrm{M}$ website views per year

At BMC, research is always in progress.

Learn more biomedcentral.com/submissions 